УДК 930.1:91:004

ББК $63 \mathrm{c5}$

\title{
Применение исторических ГИС в исследовании социальных и экономических процессов
}

\author{
М.В. Рьгалова \\ Алтайский государственный университет (Барнаул, Россия)
}

\section{Application of Historical Geographic and Information Systems in the Study of Social and Economic Processes}

M.V. Rygalova

Altai State University (Barnaul, Russia)

Рассматриваются тенденции применения геоинформационных технологий в комплексных исторических исследованиях на современном этапе. Направления, в которых большое влияние оказывает пространственный фактор (социальные, демографические, экономические), являются наиболее перспективными для применения ГИС-технологий. Если зарубежные исследователи изначально были нацелены на масштабные ГИС-проекты (национальные проекты Великобритании, США, Бельгии и др.), то отечественные исследования отличались преимущественно узкой проблематикой, небольшим хронологическим или территориальным охватом. Однако ГИС-проекты последних лет показывают существенные успехи российских специалистов в этой области. Появились масштабные проекты, охватывающие разноаспектные направления, новые группы источников, а также ГИС, доступные для ознакомления онлайн. Одно из главных преимуществ ГИС, связанное с компактным хранением данных и комплексным их анализом, стало рассматриваться исследователями как решающий фактор применения этих технологий, вытеснило уже тривиальную мысль о масштабности работы над созданием ГИС-ресурса. Примеры проектов, охватывающих комплекс показателей, демонстрируют большую целесообразность использования в качестве исследовательского инструментария ГИС.

Ключевые слова: история, историография, геоинформационные технологии, ГИС-проекты, онлайн-ГИС.

DOI 10.14258/izvasu(2019)5-12

В исторической науке все большее развитие получают направления, связанные с комплексным представлением явлений и процессов, их общей оценкой, выявлением причинно-следственных связей в контексте пространства. Специалисты в области исто-
We consider tendencies of using geographic and information technologies in complex historical researches. Some research directions (such as social, demographic, economic) includes the big influence of spatial factor. And these directions are the most promising for the application of GIS (geographic information system) technologies. Foreign researchers initially focused on large-scale GIS projects (national projects of Great Britain, USA, Belgium, etc.). Whereas Russian researchers were mainly interested in other problems, which were small chronological or territorial coverage. However, GIS projects of recent years show significant success of Russian specialists of this field. Large-scale projects were started. Nowadays they are covering different aspects, new groups of sources, as well as GIS, available for familiarization online. One of the main advantages of GIS-technologies associated with compact data storage and their complex analysis, was considered by researchers as a decisive factor in the application of these technologies. This advantage displaces the already obvious idea of the scale of work on the creation of a GIS resource. Examples of projects covering a set of indicators demonstrate the great feasibility of using GIS as a research tool.

Key words: history, historiography, geographic and information technologies, GIS projects, online GIS.

рической геоинформатики объективно выдвигают тезис о том, что пространственная компонента все более используется в гуманитарных исследованиях $[1$, с. 61-62]. В этой связи целесообразным способом работы с пространственно-временными аспекта-

\footnotetext{
*Исследование выполнено за счет гранта Российского научного фонда (проект №19-18-00180).
} 
ми и комплексами разноструктурных данных является применение геоинформационных технологий (ГИС-технологий). Однако это зачастую требует дополнительных трудозатрат, которые при получении результата исследования не всегда оказываются необходимыми. А.К. Ноулз еще в начале 2000-х гг. обозначила принцип целесообразности разработки ГИС, который заключается в том, чтобы не использовать ГИС-технологии для выполнения единичной задачи [2, p. 463].

Отечественные специалисты в области исторической геоинформатики вслед за зарубежными коллегами выдвигают идею создания масштабных георесурсов (разработка национальной ГИС России [3], фонда исторических картографических материалов [4], фонда пространственных исторических данных [5], интеграции данных, полученных в результате различных ГИС-исследований [6]).

Целью статьи является анализ использования ГИС-технологий и их возможностей в комплексных зарубежных и отечественных проектах социальноэкономической проблематики как одного из ведущих направлений использования ГИС-технологий в современной исследовательской практике.

Зарубежная практика разработки комплексных ГИС-ресурсов по социально-экономической проблематике

Наиболее масштабный блок - исследования по разработке и созданию национальных ГИСпроектов. Они представляют собой комплексные георесурсы, которые в масштабах изменяющихся государственных границ отражают социально-экономические показатели. История создания первых национальных ГИС начинается более 25 лет назад и связана с возможностями и целесообразностью представления собранных данных переписей населения [7]. Сегодня национальные ГИС являются общедоступными в среде Интернет и используются исследователями как платформа для тематических исследований [8; 9].

Зачастую использование ГИС-инструментария в исследованиях узкой тематики со временем превращает их в комплексные, позволяя объединить сразу несколько показателей, найти взаимосвязь между ними. Примерами являются исследования транспортной сети, охватывающие вопросы экономического развития, демографического роста, социального развития, урбанизации [10;11].

Особо стоит выделить направление, связанное с изучением социальной дифференциации населения по экономическим, профессиональным характеристикам. В этом контексте представляет интерес исследование использования детского труда в Португалии середины XIX - начала XXI в. на фоне экономического роста, развития инфраструктуры, демографических изменений, а также законодательства. Исследователи объединили и проанализировали комплекс показателей, которые характеризуют уровень образования, технического прогресса, профессионализм труда, юридические вопросы [12]. Американские специалисты обращаются к изучению процессов профессионализации отдельных городских районов городов Нортгемптон и Холиоке (штат Массачусетс), выделению экономического неравенства через анализ роста народонаселения, миграций. Исследователи проанализировали показатели переписей населения 1860-1910 г., данные о смертности, статистику по уплате налогов и пришли к выводам о складывании доминирующих этнических групп в отдельных профессиях, сферах занятости, существенно различающуюся по городам. Исследование представляет интерес с точки зрения охвата данных (анализ этнических, возрастных групп и их профессионального состава). Кроме того, анализ процессов на индивидуальном уровне позволил получить результаты, которые дают возможность интерпретировать социально-экономические процессы на уровне городов в целом [13].

Изучение социально-экономических факторов, влияющих на демографическую ситуацию, стало основой анализа ряда британских исследований под руководством Я. Грегори, в ходе которых удалось выявить непосредственную связь данных о местах рождения, проживания, профессионального занятия с причинами смерти и ее уровнем [14].

Геоинформационная система, включающая данные целого комплекса смежных дисциплин, представлена французскими исследователями в области народонаселения. Они создали ресурс, объединяющий данные антропологии, истории, археологии, эпидемиологии, демографии, географии и пространственного распространения эпидемиологических заболеваний в XVIII в. одного из регионов Франции Прованса [15, p. 108].

\section{Российские ГИС-исследования социально-эконо- мической проблематики}

Отечественные ГИС-проекты отличаются от зарубежных масштабностью, тематической направленностью. Российские историки начинали осваивать ГИС-технологии с узкоспециализированных тем, что по-прежнему остается приоритетным направлением.

Примером поэтапной реализации работы над комплексной ГИС является создание геоинформационной системы «Электронный каталог населенных мест Карелии XV-XX вв.». Первоначально при Петрозаводском государственном университете разрабатывались специализированные программные комплексы и вспомогательные базы данных («Электронный классификатор объектов деревян- 
ного зодчества», «Электронный каталог населенных мест Карелии XV-XXI в.», кодификатор поселений Карелии), рассчитанные на конкретные исследовательские задачи и служащие основой для последующей разработки ГИС. Кроме того, что созданная геоинформационная система охватывает значительный временной отрезок, в ней отражены ключевые показатели, которые позволяют реконструировать поселенческую структуру, исторические, социально-экономические, демографические аспекты $[16$, с. 8-10; 17$, с. $75-78]$.

Поскольку транспортная инфраструктура имеет решающее значение и определяет экономические, социальные и культурные предпосылки развития городской жизни, тамбовские исследователи под руководством М.К. Акользиной и Р.Б. Кончакова реализовали проект, в котором удается проследить взаимосвязь усложнения уровня городского хозяйства, политики и состояния транспорта. ГИС-анализ позволил установить тенденции и особенности развития уличной сети городов, транспорта, инфраструктуры. Кроме того, исследователи провели анализ влияния транспортной эволюции (в частности, строительства железных дорог) на все сферы городской жизни. Некоторые результаты проекта (карты, схемы, планы и использованные источники) размещены в свободном доступе [18].

Проект по созданию геоинформационной системы по занятиям населения Российской империи на материалах переписи населения 1897 г. изначально рассматривался как тематический. Но в процессе реализации для исследователей на его основе обозначились перспективы разработки комплексного ГИС-ресурса. В нем нашли отражение особенности социально-экономического развития на уровне уездов и сибирских городов (гендерный, национальный состав, доля городского и сельского населения, занятия, территориальные особенности инфраструктуры) [19; 20]. На базе этой ГИС разработан другой проект «Города Сибири XIX-XX вв.», отражающий социальную топографию городского пространства в Сибири (до уровня квартальной застройки) $[21 ; 22]$.

Актуальной темой становится выявление взаимосвязи экологического фактора с общим вектором развития территории. Примером является исследование состояния региональных факторов производства, различия социально-экономического развития муниципальных районов в контексте экологического и социально-экономического развития территории Волгоградской области [23].

Один из находящихся на стадии реализации отечественных ГИС-проектов выполняется бар- наульскими исследователями под руководством В.Н. Владимирова. Проект направлен на комплексную реконструкцию инфраструктуры городов юга Западной Сибири (соотношение факторов промышленного роста, развития городского хозяйства, роста инфраструктуры, экологического состояния) [24; 25].

Еще одним проектом, находящимся в стадии разработки, является создание ГИС «Комплексная оценка социально-экономического развития регионов Российской империи», включающей территорию Степного края и Туркестана. Проект направлен на выявление и представление в виде ГИС комплексных показателей модернизации пространства в XIX-XX вв. Он рассчитан на поэтапную реализацию и предусматривает разработку баз данных, ГИС с последующей ее трансформацией на интернет-платформе (размещение онлайн-ГИС). Особенностью проекта является не только территориальный охват (азиатские регионы Российской империи), но и введение в оборот исторических источников, данных статистики, ранее не использующихся в исследовательских целях. На данной основе предполагается оценка уровня жизни в регионах, анализ направлений развития экономики и промышленности, их соотношение, изучение сфер занятости населения. Комплексность и разнородность источников (статистических таблиц, нарративных источников, региональных обзоров, картографических и топографических материалов, архивных данных), положенных в основу геоинформационной системы, позволит объединить массивы информации по социально-экономическому развитию территории, обнаружить взаимосвязи, отметить тенденции.

Итак, обзор исторических исследований социально-экономической тематики показывает интерес и большой опыт в этом направлении работы с ГИС-технологиями. Это связано с возможностями объединения в едином ресурсе комплекса источников и показателей. Кроме того, такие исследования охватывают различные сферы общественного развития, большие наборы данных, взаимосвязанные между собой, показатели, влияющие друг на друга (уровень развития транспортной инфраструктуры и численность населения, рост промышленности, торговли и сферы занятости населения и проч.), ГИС-технологии являются сегодня предпочтительным инструментом, поскольку обладают функциональными возможностями для обогащения исследования за счет объединенного анализа данных, поиска взаимосвязей между ними и визуализацией итоговых и промежуточных результатов. 


\section{Библиографический список}

1. Фролов А.А. Динамическая карта как основа исторической карты в среде ГИС // Историческая информатика. 2017. № 2. DOI: 10.7256/2306-0891.2017.1.23010.

2. Knowles A.K. Introduction // Social Science History. 2000. Vol. 24. No. 3. DOI: 10.1215/01455532-24-3-451.

3. Фролов А.А. На пути к национальной ГИС России: два подхода к интеграции исследовательских геоданных // Историческая информатика. 2019. № 1. DOI: 10.7256/2585-7797.2019.1.29508.

4. Гришин Е.С. Фонд историко-картографических материалов как средство унификации исторических ГИС и цифровой картографии // Историческая информатика. 2019. № 1. DOI: 10.7256/2585-7797.2019.1.29508.

5. Владимиров В.Н., Крупочкин Е.П. О необходимости учреждения и развития фонда пространственных исторических данных // Историческая информатика. 2019. № 1. DOI: 10.7256/2585-7797.2019.1.29508.

6. Владимиров В.Н., Фролов А.А. Всероссийский научный семинар «Геоинформационные системы в исторических исследованиях: интеграционные подходы» // Историческая информатика. 2019. № 1. DOI: $10.7256 / 2585-$ 7797.2019.1.29508.

7. Southall H. Rebuilding the Great Britain Historical GIS, Part 1: Building an Indefinitely Scalable Statistical Database // Historical Methods: A Journal of Quantitative and Interdisciplinary History. 2011. Vol.44. No. 3. DOI: 10.1080/01615440.2011.589774.

8. Gregory I. The Great Britain Historical GIS // Historical Geography. 2005. Vol. 33.

9. Pierau K. Entwurf eines geographisch-historischen Informationsystems: GEOHIST // Historical and Social Research. 1993. Vol. 18. No. 4.

10. Schwartz R.M. Rail Transport, Agrarian Crisis, and the Restructuring of Agriculture: France and Great Britain Confront Globalization, 1860-1900 // Social Science History. Vol. 34. No. 2. 2010. DOI: 10.1215/01455532-2009-026.

11. Donaldson D., Hornbeck R. Railroads and American Economic Growth: New Data and Theory. URL: http:// citeseerx.ist.psu.edu/viewdoc/download?doi=10.1.1.221.6746 \&rep=rep1\&type $=$ pdf (accessed 18.06.2019).

12. Goulart P., Bedi A.S. The Evolution of Child Labor in Portugal, 1850-2001 // Social Science History. 2017. Vol. 41. No. 2. DOI: 10.1017/ssh.2017.3.

13. Leonard S.H., Robinson C., Anderton D.L. Immigration, Occupation, and Inequality in Emergent Nineteenth-Century New England Cities // Social Science History. 2017. Vol. 41. No. 4. DOI: 10.1017/ssh.2017.26.

14. Gregory I. Longitudinal Analysis of Age- and GenderSpecific Migration Patterns in England and Wales // Social Science History. 2000. Vol. 24. No. 3. DOI: 10.1215/0145553224-3-471.
15. Seguy I., Bernigaud N., Bringe A., Tzortzis S. A Geographic Information System for the Study of Past Epidemics: The 1705 Epidemic in Martigues (Bouches-du-Rhône, France) // Historical Studies on Mortality, special issue, Canadian Studies in Population. 2012. Vol. 39. No. 3-4. DOI: 10.25336/ P6X024.

16. Жуков А.Ю., Лялля Е.В. ГИС «Электронный каталог населенных мест Карелии XV-XXI вв.» // Ученые записки Петрозаводского государственного университета. 2010. № 7.

17. Шредерс А.М., Лялля Е.В. Практика применения ГИС в историко-культурных исследованиях // Историческая информатика. Информационные технологии и математические методы в исторических исследованиях и образовании. 2012. № 1.

18. Развитие транспортной инфраструктуры городов Тамбовской губернии в XVIII - начале XX в. Проект РГНФ 10-01-54510a/Ц. URL: https://sites.google.com/site/ gortransort/home (дата обращения: 18.06.2019).

19. Брюханова Е.А. Геоинформационные технологии в изучении занятий населения Российской империи на рубеже XIX-XX вв. (по материалам переписи 1897 г.) // Информационный бюллетень Ассоциации «История и компьютер». № 43. 2015.

20. Брюханова Е.А., Чекрыжова О.И. Пространственный анализ социально-экономических данных переписи 1897 г.: статистический и картографический методы (на примере уездов Сибири) // Информационный бюллетень Ассоциации «История и компьютер». № 43. 2015.

21. Рыгалова М.В., Брюханова Е.А. Информационные технологии в изучении исторической топографии городов Западной Сибири на рубеже XIX-XX вв. // Исторический курьер. 2018. № 2. Статья 4. URL: http://istkurier.ru/ data/2018/ISTKURIER-2018-2-04.pdf/. DOI: 10.31518/26189100-2018-2-4 (дата обращения: 23.06.2019).

22. Крупочкин Е.П., Брюханова Е.А., Чекрыжова О.И. Опыт разработки исторической web-ГИС в контексте изучения социальной топографии городов Сибири в XIX в. // От карты прошлого - к карте будущего. Пермь, 2017. Т. 2.

23. Бодрова В.Н. Методика комплексного исследования экологических и социально-экономических процессов на территории Волгоградской области в геоинформационной системе // Вестник Волгоградского государственного университета. Серия 11: Естественные науки. 2014. № 2.

24. Владимиров В.Н., Крупочкин Е.П. Геоинформационное картографирование динамики инфраструктуры городов в исторических реконструкциях (на примере Барнаула и Бийска) // Информационный бюллетень Ассоциации «История и компьютер». № 47. 2018.

25. Сарафанов Д.Е. Создание исторической ГИС Барнаула: к постановке темы // Информационный бюллетень Ассоциации «История и компьютер». № 46. 2017. 